\title{
COMO A CORÉIA DE SYDEHAM É TRATADA NO RIO DE JANEIRO
}

AO EDITOR - A respeito do artigo " Como a Coréia de Sydeham é tratada no Rio de Janeiro ?" de Vinicius Castro Souza e col. no Vol. 65(3-A), de Setembro de 2007, gostaria de chamar a atenção sobre a citação de $n^{\circ} 7$ "Diament A, Cypel S. Neurologia Infantil. São Paulo: Atheneu, 1984".

Devo ressaltar os seguintes pontos:

a) Cita o nosso livro e não o artigo pertinente sobre CS escrito por mim desde a $1^{\text {a }}$ edição, de 1980;

b) Não cita a que edição do livro se referiram os AA, colocando apenas a data: 1984;

c) As edições do Livro Neurologia Infantil são: 1980 é a primeira e foi da Sarvier - objeto do Prêmio Jabuti naqueles anos (1980/81); a $2^{\text {a }}$ edição foi de 1989, pois houve mudança de editora, passando à Atheneu (foi em homenagem ao Mestre Lefèvre que havia falecido em 1981); a $3^{\text {a }}$ edição foi em 1995, ainda pela Atheneu e, a 4 a edição foi de 2005; em todas, o Capítulo de CS foi de minha autoria, pois foi objeto de minha tese de Docência-livre (em 1971);

d) Portanto, a citação certa, se fosse, por exemplo a 4 a edição, teria que ser:

Diament A. Coréia de Sydenham. In Neurologia Infantil. Diament A, Cypel S (Eds). 4.Ed. Rio de Janeiro, São Paulo, Ribeirão Preto, Belo Horizonte: Atheneu, 2005:1093.
Resolvi escrever à redação de Arquivos, pois sei como são cuidadosos seus editores e revisores.

Atenciosamente,

\section{Aron Diament}

RESPOSTA DOS AUTORES - Agradecemos a leitura cuidadosa e interessada do nosso trabalho.

Esclarecemos que a referência é: Diament $A$ e Cypel S. Neurologia Infantil, $3^{a}$ Edição. São Paulo: Editora Atheneu, 1996.

Como foram consultados mais capítulos não se citou cada um isoladamente. $O$ artigo publicado em Arquivos Neuropsiquiatria 1972;30:187 não foi incluído nas referências devido a temática específica do presente trabalho ser sobre tratamento e não sobre os exames complementares. Apenas por este motivo tal referência não foi utilizada na discussão dos nossos resultados.

Com os demais autores, atenciosamente,

\section{KETOGENIC DIET FOR THE TREATMENT OF REFRACTORY EPILEPSY}

AO EDITOR - Eu li com muito interesse o artigo Ketogenic Diet for the Treatment of Refractory Epilepsy, por Dra. Alessandra Freitas e os seus colegas, nos Arquivos de Neuro-Psiquiatria Junho 2-B, 2007. Entre os anos 1954 e 1958, no Childrens Mercy Hospital, Kansas City, Missouri, USA, eu administrei uma enfermaria com 12 leitos em que a dieta cetogênica foi usada no tratamento de epilepsia. As crianças tinham entre 5 e 14 anos de idade, e cada criança foi hospitalizada durante mais os menos 60 dias.

Como os autores deste artigo, eu achei a dieta cetogênica eficaz em crianças cujas convulsões não foram controladas com remédios.

Mas eu tive dois problemas. (1) A enfermeira teve um cheiro desagradável aos pacientes, os seus pais e o pessoal do hospital. Todavia, isso foi um pequeno problema. (2) Um grande problema foi à manutenção desta dieta quando as crianças saíram do hospital e voltaram para suas casas. Somente $30 \%$ destas crianças continuavam na dieta 6 meses depois de saírem do hospital. As crianças não gostaram da dieta, especialmente quando elas viram os outros membros da família com dietas normais. Também, as mães tinham que preparar um tipo de comida para as crianças epilépticas e um outro tipo de comida para o resto da família. Isso custou dinheiro extra, e exigiu trabalho extra.

Todavia, o Childrens Mercy Hospital não foi um 
hospital típico. Este hospital aceitou crianças de pequenas cidades e regiões rurais do estado de Missouri. A maioria dos pais era da classe operária, e alguns eram de classe pobre. O nível de escolaridade dos pais era inferior do que o nível de escolaridade da população americana em geral. Nós achamos que a dieta cetogênica foi mais eficaz nos lares onde os pais eram mais esclarecidos e tinham um nível econômico melhor.

\section{A.H. Chapman}

Serviços Neuropsiquiátricos Vitória da Conquista / BA.

RESPOSTA DA AUTORA - Caro colega Dr. A.H. Chapman, agradeço seu interesse em nosso trabaIho e parabenizo-o pela sua experiência neste assunto. Quanto às suas dúvidas esclareço que:

1) Nós realizamos a dieta cetogênica no Instituto da Criança do Hospital das Clínicas da Universidade de São Paulo (USP). Nosso hospital, por ser uma referência no atendimento de pacientes do SUS, não dispõe de leitos específicos para a dieta; portanto, os pacientes eram internados para a introdução da dieta individualmente e na enfermaria comum. Essa internação era breve (cerca de 5 a 7 dias) e talvez por isso não tenhamos observado tal efeito. Atualmente, a dieta é introduzida ambulatorialmente, sem a necessidade de internação hospitalar.

2) Nossa população, embora heterogênea, também era de baixa renda; entretanto, temos o suporte eficiente do serviço social e quando necessário do serviço de psicologia. Tivemos poucos casos de desistência por problemas relacionados à dinâmica familiar. Observamos que uma boa orientação pré-introdução da dieta foi fundamental para essa adesão. Nossos pacientes vêm sempre de outros serviços de epilepsia de difícil controle, talvez esse também seja um fator que ajude à adesão, visto que são de famílias que já experimentaram vários tratamentos.

Alessandra Freitas 